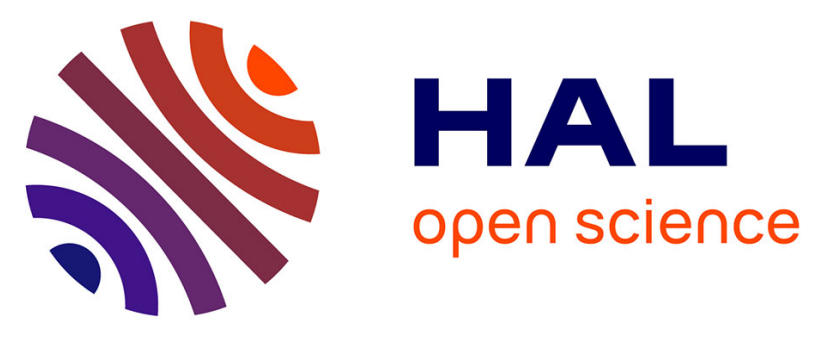

\title{
Microsatellite mapping of quantitative trait loci affecting female reproductive tract characteristics in Meishan x Large White F2 pigs
}

Adalberto Rosendo-Ponce Rosendo, Nathalie N. Iannuccelli, Hélène Gilbert, Juliette Riquet, Yvon Y. Billon, Yves Y. Amigues, Denis Milan, Jean Pierre Bidanel

\section{To cite this version:}

Adalberto Rosendo-Ponce Rosendo, Nathalie N. Iannuccelli, Hélène Gilbert, Juliette Riquet, Yvon Y. Billon, et al.. Microsatellite mapping of quantitative trait loci affecting female reproductive tract characteristics in Meishan x Large White F2 pigs. Journal of Animal Science, 2012, 90 (1), pp.37-44. 10.2527/jas.2011-3989 . hal-01000225

\section{HAL Id: hal-01000225 https://hal.science/hal-01000225}

Submitted on 28 May 2020

HAL is a multi-disciplinary open access archive for the deposit and dissemination of scientific research documents, whether they are published or not. The documents may come from teaching and research institutions in France or abroad, or from public or private research centers.
L'archive ouverte pluridisciplinaire HAL, est destinée au dépôt et à la diffusion de documents scientifiques de niveau recherche, publiés ou non, émanant des établissements d'enseignement et de recherche français ou étrangers, des laboratoires publics ou privés. 


\section{JOURNAL OF ANIMAL SCIENCE}

The Premier Journal and Leading Source of New Knowledge and Perspective in Animal Science

\section{Microsatellite mapping of quantitative trait loci affecting female reproductive tract} characteristics in Meishan $\times$ Large White $F_{2}$ pigs

A. Rosendo, N. Iannuccelli, H. Gilbert, J. Riquet, Y. Billon, Y. Amigues, D. Milan and J. P. Bidanel

J ANIM SCI 2012, 90:37-44.

doi: 10.2527/jas.2011-3989 originally published online September 23, 2011

The online version of this article, along with updated information and services, is located on the World Wide Web at:

http://www.journalofanimalscience.org/content/90/1/37 


\title{
Microsatellite mapping of quantitative trait loci affecting female reproductive tract characteristics in Meishan $\times$ Large White $F_{2}$ pigs $^{1}$
}

\author{
A. Rosendo, ${ }^{*}$ N. Iannuccelli, $\dagger$ H. Gilbert,* J. Riquet, $\dagger$ Y. Billon, $\ddagger$ Y. Amigues, $§$ \\ D. Milan, $\dagger$ and J. P. Bidanel ${ }^{* 2}$
}

*INRA, UMR1313 Génétique Animale et Biologie Intégrative F-78350 Jouy-en-Josas, France; †INRA, UMR444

Laboratoire de Génétique Cellulaire F-31320 Castanet-Tolosan, France; †INRA, UE967 Génétique Expérimentale en Productions Animales, F-17700 Surgères, France; and §LABOGENA, F-78350 Jouy-en-Josas, France

\begin{abstract}
A QTL analysis of female reproductive data from a 3-generation experimental cross between Meishan and Large White pig breeds is presented. Six $\mathrm{F}_{1}$ boars and $23 \mathrm{~F}_{1}$ sows, progeny of 6 Large White boars and 6 Meishan sows, produced $502 \mathrm{~F}_{2}$ gilts whose reproductive tract was collected after slaughter at 30 $\mathrm{d}$ of gestation. Five traits [i.e., the total weight of the reproductive tract, of the empty uterine horns, of the ovaries (WOV), and of the embryos], as well as the length of uterine horns (LUH), were measured and analyzed with and without adjustment for litter size. Animals were genotyped for a total of 137 markers covering the entire porcine genome. Analyses were carried out based on interval mapping methods, using a line-cross regression and a half-full sib maximum likelihood test. A total of 18 genome-wide significant $(P<0.05)$ QTL were detected on 9 different chromosomes (i.e., SSC 1, $5,6,7,9,12,13,18$, and X). Five genome-wide significant QTL were detected for LUH, 4 for weight of the
\end{abstract}

empty uterine horns and WOV, 2 for total weight of the reproductive tract, and 1 for weight of the embryos. Twenty-two additional suggestive QTL were also detected. The largest effects were obtained for LUH and WOV on SSC13 (9.2 and 7.0\% of trait phenotypic variance, respectively). Meishan alleles had both positive (e.g., on SSC7) and negative effects (e.g., on SSC13) on the traits investigated. Moreover, the QTL were generally not fixed in founder breeds, and opposite effects were in some cases obtained in different families. Although reproductive tract characteristics had only a moderate correlation with reproductive performances, most of the major QTL detected in this study were previously reported as affecting female reproduction, generally with reduced significance levels. This study thus shows that focusing on traits with high heritability might help to detect loci involved in low heritability major traits for breeding.

Key words: gene mapping, pig, quantitative trait locus, reproductive tract

(C) 2012 American Society of Animal Science. All rights reserved.

J. Anim. Sci. 2012. 90:37-44 doi:10.2527/jas.2011-3989

\section{INTRODUCTION}

Some native pig breeds of China, such as the Taihu set of breeds, are known to exhibit high reproductive performances, in particular larger litters than conventional maternal breeds (Bidanel et al., 1989, Lee and Haley, 1995). The physiological and genetic bases of this increased prolificacy remain largely unknown. Sev-

\footnotetext{
${ }^{1}$ The experimental program was funded by the European Union (Bridge and Biotech+ programs), INRA (Department of Animal Genetics and AIP "Structure des génomes animaux"), and the "Groupement de recherches et études sur les génomes." Economic support for the senior author by CONACYT (Consejo Nacional de Ciencia y Tecnología) and SEP (Secretaría de Educación Pública), Mexico, is gratefully acknowledged.

${ }^{2}$ Corresponding author: jean-pierre.bidanel@jouy.inra.fr

Received February 19, 2011.

Accepted August 30, 2011.
}

eral studies have been implemented to search for QTL explaining the difference in reproductive traits between Meishan and Western breeds (e.g., Rohrer et al., 1999; Bidanel et al., 2008; Noguera et al., 2009). Yet, the number of QTL affecting reproduction traits identified so far is limited compared with other traits of interest (Bidanel and Rothschild, 2002), and most of them are only suggestive QTL.

Uterine capacity is a major component of litter size at birth (Bennett and Leymaster, 1989). Meishan sows have been shown to have a better uterine capacity than British Large White sows (Lee and Haley, 1995). Though variations in uterine capacity are not solely due to variations in uterine dimensions, it may be hypothesized that the physical characteristics of the uterus contribute to some extent to differences in uterine capacity or litter size (e.g., Wu et al., 1987). As most body composition traits, reproductive tract measurements have 
rather high heritability values, which make it easier to find QTL than for lowly heritable traits. The QTL affecting these measurements are then also expected to be associated with variations in litter traits. Yet, very few results QTL are available for reproductive tract characteristics in the PigQTLdb (http://www.animal genome.org). These traits were measured at $30 \mathrm{~d}$ of gestation within the PorQTL program, a large experiment aimed at detecting QTL for a large number of traits of interest in a Large White $\times$ Meishan $\mathrm{F}_{2}$ pig population (Bidanel et al., 2001; Milan et al., 2002; Quintanilla et al., 2003). This paper reports the results of a wholegenome scan aimed at mapping QTL affecting these female reproductive tract measurements.

\section{MATERIALS AND METHODS}

Animal care followed the general guidelines outlined in the European welfare regulation (directive 91/630/ $\mathrm{EC})$.

\section{Animals and Data Recording}

A 3-generation resource population was developed between 1991 and 1997 at the French National Institute of Agronomic Research experimental research farm Le Magneraud (Surgères, Charente-Maritime), by first mating 6 unrelated Large White boars to 6 lowly related Meishan sows ( 1 boar/sow). The 12 founder animals were tested and found to be free of the mutation at the ryanodyne receptor locus, which is responsible for halothane susceptibility. One boar and 4 gilts were kept for breeding in each of the 6 litters produced (except in 1 litter where only 3 females were available). Three or $4 \mathrm{~F}_{1}$ females were assigned to each of the $\mathrm{F}_{1}$ boars and were mated to produce $\mathrm{F}_{2}$ families. A total of $573 \mathrm{~F}_{2}$ female and 530 male pigs were used for QTL mapping (Bidanel et al., 2001).

The $\mathrm{F}_{1}$ sows were managed under a batch farrowing system, with a 3 -wk interval between contiguous batches. The $\mathrm{F}_{2}$ females were raised in Le Magneraud, with the exception of 68 females raised in another experimental herd (SESP, Rouillé, Vienne) in 1992, as described in Bidanel et al. (2001, 2008). Sexually mature gilts were submitted to a synchronization treatment with a progestagen at 26 or 29 wk of age. The gilts were inseminated twice at a 12-h interval on the estrus after the progestagen treatment with semen from Piétrain boars and weighed. The gilts were then slaughtered at 1 mo of gestation. The reproductive tract of pregnant gilts was collected at the slaughterhouse and immediately dissected to measure its main characteristics.

The whole reproductive tract was weighed. It was then placed on a flat surface and cut free of ligaments at the bifurcation of the 2 horns and at the utero-tubal junction to separate out the uterine horns, the ovaries, and the vagina plus cervix set. Each element was weighed, and the length of each uterine horn was measured with a flexible tape without stretching. Uterine horns were then cut longitudinally and embryos and placentas removed sequentially. Each embryo was examined and subjectively classified as viable or degenerating. The total embryo weight was then measured for each uterine horn. Ovaries were weighed and ovulation rate was determined by counting the number of corpora lutea on each ovary after dissection.

\section{Traits Analyzed}

Five traits were defined and analyzed from the above-mentioned measurements [i.e., the total weight of the reproductive tract (TWRT), the weight (WUH) and the length (LUH) of 2 empty uterine horns, and the total weights of embryos (WEMB) and of ovaries (WOV)]. The number of records, overall means, and phenotypic SD of the 5 traits studied are shown in Table 1.

\section{Genotyping and Map Construction}

All $\mathrm{F}_{2}$ males, their 29 parents, and 12 grandparents were genotyped for 136 microsatellite markers and the major histocompatibility complex. The markers covered all autosomes and the $\mathrm{X}$ chromosomes, with 3 to 12 markers on each. Genotypes were obtained as described by Bidanel et al. (2001). Multipoint linkage analyses were carried out with the 2.4 version of the CriMap software (Green et al., 1990). Recombination units were then transformed to map distances using the Haldane mapping function. The average distance between adjacent markers was $22.0 \mathrm{cM}$ on the sex-averaged map (Bidanel et al., 2001).

\section{Statistical Analyses}

The data $\tilde{y}$ used for QTL mapping were obtained as residuals from a linear model including the fixed effects of contemporary group, as well as gilt BW at mating and days of gestation (except WOV) as covariates. Residual correlations were computed as Pearson correla-

Table 1. Descriptive statistics for the 5 traits analyzed

\begin{tabular}{llccc}
\hline \hline Trait & Abbreviation & $\mathrm{n}$ & Mean & SD \\
\hline Total weight of the reproductive tract, $\mathrm{kg}$ & TWRT & 465 & 3.06 & 0.84 \\
Weight of empty uterine horns, kg & WUH & 465 & 1.18 & 0.23 \\
Length of uterine horns, $\mathrm{m}$ & LUH & 465 & 3.54 & 0.67 \\
Weight of ovaries, $\mathrm{g}$ & WOV & 502 & 14.7 & 2.41 \\
Weight of embryos, log, $\mathrm{g}$ & WEMB & 465 & 2.58 & 0.48 \\
\hline
\end{tabular}


tion coefficients between residuals. Additional analyses were performed by adding ovulation rate (for WOV) or number of viable embryos (for TWRT, WUH, LUH, and WEMB) as covariates. The analyses were performed using the GLM procedure (SAS Inst. Inc., Cary, $\mathrm{NC}$ ).

Two types of interval mapping analyses were performed: 1) a line cross analysis assuming that founder populations are fixed for different QTL alleles (referred to as the LC model hereafter), and 2) a model assuming that the $\mathrm{F}_{2}$ population is a mixture of full- and half-sib families, with no assumption about the number of QTL alleles and allele frequencies within the founder populations (referred to as the HFS model hereafter).

LC Model. The LC model used assumed a biallelic QTL with alternative alleles fixed in founder breeds, $Q$ in Meishan and $q$ in Large White animals. Denoting the effects of $Q Q, Q q / q Q$, and $q q$ as $a, d$, and $-a$, respectively, the adjusted performance $\tilde{y}_{i}$ of an $\mathrm{F}_{2}$ offspring $i$ can be written as

$$
\tilde{y}_{i}=\mu+c_{a i} a+c_{d i} d+e_{i},
$$

where $\mu$ is the population mean, $c_{a i}$ and $c_{d i}$ are the coefficients of additive $(a)$ and dominance $(d)$ components, respectively, for animal $i$ at a given putative position in the genome, and $e_{i}$ is the residual error. The $c_{a i}$ and $c_{d i}$ were computed as $c_{a i}=\operatorname{Prob}_{i}(Q Q)-\operatorname{Prob}_{i}(q q)$ and $c_{d i}=\operatorname{Prob}_{i}(Q q)+\operatorname{Prob}_{i}(q Q)$, where $\operatorname{Prob}_{i}(X X)$ is the probability of having genotype $X X$ for animal $i$. The genotype probabilities were computed as described in Haley et al. (1994). At each tested location (each centimorgan), an $F$-ratio was computed to compare the hypothesis with 1 QTL (H1) vs. the hypothesis of no QTL on the chromosome. Reported estimates for $a$ and $d$ were those obtained at the location with the greatest $F$-ratio. A positive $a$ will then correspond to Meishan alleles increasing the trait value, a positive $d$ to dominance of the Meishan alleles on the Large White alleles. The analyses were carried out using the QTL Express software (Seaton et al., 2002).

Significance thresholds were empirically determined at the chromosome level $\left(\mathbf{P}_{\mathbf{c}}\right)$ by first performing 1,000 permutations of the trait values against the genotypes. Then, for chromosome-wide (CW) significant chromosomal regions $\left(\mathrm{P}_{\mathrm{c}}<0.05\right), 9,000$ additional permutations were carried out to obtain more precise distributions of the test statistics under $\mathrm{H} 0$ and to accurately determine genome-wide $(\mathbf{G W})$ significance thresholds. These GW significance levels $\left(\mathbf{P}_{\mathrm{g}}\right)$ were obtained, applying an approximate Bonferroni correction with factor nc to significance levels $\mathrm{P}_{c}$ [i.e., as a solution to $\mathrm{P}_{\mathrm{g}}$ $\left.=1-\left(1-\mathrm{P}_{\mathrm{c}}\right)^{\mathrm{nc}}\right]$, where $\mathrm{P}_{\mathrm{g}}$ is a $\mathrm{GW}$ test probability and $\mathrm{nc}$ is the number of chromosomes, which gives $\mathrm{P}_{\mathrm{c}}$ $=0.0027$ for $\mathrm{P}_{\mathrm{g}}=0.05$ and $\mathrm{nc}=19$ (Knott et al., 1998). Chromosome-wide thresholds at $P<0.05$ varied slightly depending on chromosomes and traits, but they were on average equal to $F=7.6$ and 5.4, respectively, with 2 (autosomes) and 1 (chromosomes X) df in the numerator. Genome-wide significance thresholds (0.05 false-positives per genome scan) were on average equal to $F=13.0$ and 8.5 , respectively, for $F$-ratios with 1 and $2 \mathrm{df}$ in the numerator.

Outbred Model. The HFS analyses with a single QTL model were carried out to better take into account the possibility that a QTL segregates in 1 or both founder populations. The $\mathrm{F}_{2}$ population was supposed to be structured in 24 full-sib families nested within 6 independent sire families. Hence, a dam mated to different sires was considered as a different dam for each sire. Test statistics were computed with 1-cM steps along the genome, as the ratio of likelihoods under the hypotheses of one (H1) vs. no (H0) QTL at the position considered. Under H1, a QTL with a gene substitution effect $(\alpha)$ for each sire and each dam was fitted to the data (Bidanel et al., 2001). Significance thresholds were determined empirically by simulating trait values under a polygenic infinitesimal model and a normal distribution of performance traits (Le Roy et al., 1998) for the $\mathrm{F}_{2}$ progeny. Simulations were preferred to permutations to ensure an extensive description of the empirical distribution of the test statistic under $\mathrm{H} 0$ while respecting the structures of the families (Churchill and Doerge, 2008); permutations should be carried out within fullsib families, which had a too limited size in our data set to guarantee accurate estimation of the thresholds. As for the LC model, 1,000 simulations were first performed for each chromosome $\times$ trait combination to determine CW significance levels $\left(\mathrm{P}_{\mathrm{c}}\right)$. Then, for CW significant chromosomal regions $\left(\mathrm{P}_{\mathrm{c}}<0.05\right), 9,000$ additional simulations were carried out to accurately determine GW significance thresholds using a Bonferroni correction as described previously. For each QTL reaching a CW significance level of $5 \%$, additional tests with models ignoring dam QTL effects within sire families were performed, so the sire status for the QTL was tested. To avoid a large number of additional computations, sires whose likelihood ratio tests were less than the value of a $\chi^{2}$ distribution with $1 \mathrm{df}$ and for a type I error of $5 \%(=3.84)$ were considered homozygous for the locus. Simulations performed in a limited number of cases showed that this threshold slightly underestimated the real threshold, but a low threshold was considered adequate to detect the existence of homozygous sires at the QTL. Finally, the average substitution effect of each QTL was computed as the mean of the substitution effects estimated for the heterozygous sires. A positive substitution effect corresponded to an increase of the trait value due to the Meishan alleles.

\section{RESULTS}

Residual correlations between the 5 traits are shown in Table 2. The 3 uterine measurements (i.e., TWRT, WUH, and LUH) were strongly correlated (correlation $\rho>0.50)$. These measurements also had strong correlations with embryo weight, but were weakly correlated with the WOV. 
Table 2. Coefficients of correlation between the 5 traits studied

\begin{tabular}{lccrl}
\hline \hline Trait $^{1}$ & WUH & LUH & WOV & WEMB \\
\hline TWRT & $0.79^{* * *}$ & $0.59^{* * *}$ & $0.18^{* * *}$ & $0.74^{* * *}$ \\
WUH & & $0.55^{* * *}$ & $0.24^{* * *}$ & $0.48^{* * *}$ \\
LUH & & & $-0.03 \mathrm{NS}$ & $0.45^{* * *}$ \\
WOV & & & & $0.11^{*}$ \\
\hline
\end{tabular}

${ }^{1}$ TWRT $=$ total weight of the reproductive tract; WUH $=$ weight of empty uterine horns; LUH = length of uterine horns; WOV = weight of ovaries; WEMB = weight of embryos.

${ }^{*} P<0.05 ;{ }^{* *} P<0.001 ; \mathrm{NS}=$ not significant $(P>0.10)$.

Residual correlations between the 5 traits studied and the reproductive traits investigated in Bidanel et al. (2008) are given in Table 3. Gilt weight at mating had low to moderate positive correlations with the 5 traits (0.07 to 0.31$)$. Correlations with ovulation were moderate (0.34 to 0.47). With the exception of WOV, correlations were rather strong with the number of viable embryos (0.47 to 0.80$)$ and with embryo survival at $30 \mathrm{~d}$ of gestation (0.38 to 0.72 ).

Results of QTL mapping analyses showing associations with at least a CW level of significance obtained using both LC and HFS models are given in Table 4 for uterine measurements and Table 5 for ovarian and embryo weights. When 1 of the 2 methods gave nonsignificant results, the maximum value of the test statistics and the corresponding position are still provided, but not estimates of QTL effects, which are not significant. In addition to the results obtained for the base traits (i.e., TWRT, WUH, LUH, WOV, and WEMB), results of analyses on traits adjusted for ovulation rate or number of viable embryos (NVE) are also provided.

Genome-wide significant QTL were detected on 7 different chromosomes (i.e., SSC 1, 5, 7, 9, 13, 18, and $\mathrm{X}$ ) using the LC model. Two additional chromosomes (i.e., SSC 6 and 12) carried GW significant QTL detected only with the HFS model. The SSC $1 \mathrm{GW}$ significant QTL was close to SW396. It affected LUH and explained a smaller fraction of the phenotypic variance when the data were adjusted for number of embryos (2.7 vs. $4.4 \%$ ). Meishan alleles had a positive and partly dominant effect. This QTL was confirmed with HFS analyses, which additionally showed that only 3 of the $F_{1}$ sires were likely to be heterozygous for the QTL, so that the LC estimate of additive genetic effect (a) was biased downward. At least another CW significant QTL affecting WUH and TWRT was detected on SSC1. In fact, 2 most likely regions, one in the S0155S0374 interval and the second one in the neighborhood of SW1301, were detected depending on the analyses. The LC analyses located the QTL affecting WUH in the vicinity of SW1301, but HFS analyses located it close to SW1828 (WUH) or in the S0155-S0374 interval for WUH adjusted for the number of embryos. The situation was even more complex for TWRT because the most likely positions for LC and HFS were inverted when adjusting for NVE. A more detailed examination of likelihood ratio curves showed that the overall profile was very flat due to large family differences in the QTL most probable position (Figure 1), which suggests that different QTL may be segregating in different families.

On SSC5, a QTL mainly affecting WUH and located in the SW2425 to SW1134 interval was detected using the LC model only. Meishan alleles were dominant over Large White alleles and had low to moderate additive effects. A QTL affecting LUH was detected on SSC 6 with the HFS model only. Both negative and positive QTL substitution effects of similar magnitude were obtained in different sire families. Similar opposite substitution effects according to sire family were obtained for TWRT and, to a lesser extent, for LUH and WUH, on SSC12. In both cases, positive and negative QTL substitution effects probably canceled each other out and could not be detected when using the simpler LC model.

The LRA1 to SW352 region on SSC 7 had strong effects on both WUH and LUH, with positive and partly dominant effects of Meishan alleles explaining up to $6.3 \%$ of the phenotypic variance. The HFS analyses tended to show that the QTL was not segregating in the $6 \mathrm{~F}_{1}$ sire families and even had opposite effects on WUH in different families. A second GW significant QTL located at about $30 \mathrm{cM}$ from the former one affected WOV, with negative dominant effects of Meishan alleles.

Contrary to the QTL affecting LUH on SSC1 and WUH on SSC5, the QTL located on SSC 9 close to SW2093, and on SSC 13 between S0223 and SW225, explained a larger fraction of the phenotypic variance of reproductive tract characteristics when the data were adjusted for NVE. Meishan alleles had in both cases negative and partially recessive effects explaining up to 4.6 and $10.3 \%$ of trait phenotypic variance, respectively. No opposite effect according to sire family was detected, but the QTL segregation could not be validated in all sire families. Quantitative trait loci were also detected for WOV on both chromosomes, in the same position on SSC13, but at a somewhat different location on SSC9 [in the SW911 to SW2401 interval

Table 3. Coefficients of correlation between the 5 traits studied and reproductive traits

\begin{tabular}{lcccc}
\hline \hline Trait $^{1}$ & $\mathrm{WTM}^{2}$ & $\mathrm{OR}^{2}$ & $\mathrm{NVE}^{2}$ & $\mathrm{ES}^{2}$ \\
\hline TWRT & $0.19^{* * *}$ & $0.31^{* * *}$ & $0.77^{* * *}$ & $0.66^{* * *}$ \\
WUH & $0.27^{* * *}$ & $0.35^{* * *}$ & $0.55^{* * *}$ & $0.40^{* * *}$ \\
LUH & $0.21^{* * *}$ & $0.24^{* * *}$ & $0.47^{* * *}$ & $0.38^{* * *}$ \\
WOV & $0.31^{* * *}$ & $0.47^{* * *}$ & $0.18^{* * *}$ & $-0.07 \dagger$ \\
WEMB & $0.07 \mathrm{NS}$ & $0.24^{* * *}$ & $0.80^{* * *}$ & $0.72^{* * *}$ \\
\hline
\end{tabular}

${ }^{1}$ TWRT $=$ total weight of the reproductive tract; WUH $=$ weight of empty uterine horns; LUH = length of uterine horns; WOV = weight of ovaries; WEMB = weight of embryos.

${ }^{2} \mathrm{WTM}=$ weight at mating; $\mathrm{OR}=$ ovulation rate; $\mathrm{NVE}=$ number of viable embryos at $30 \mathrm{~d}$ of gestation; ES = embryo survival at $30 \mathrm{~d}$ of gestation.

$$
\dagger P<0.10 ;{ }^{* * *} P<0.001 ; \mathrm{NS}=\text { not significant }(P>0.10) .
$$


Table 4. Results of QTL analyses for reproductive tract measurements

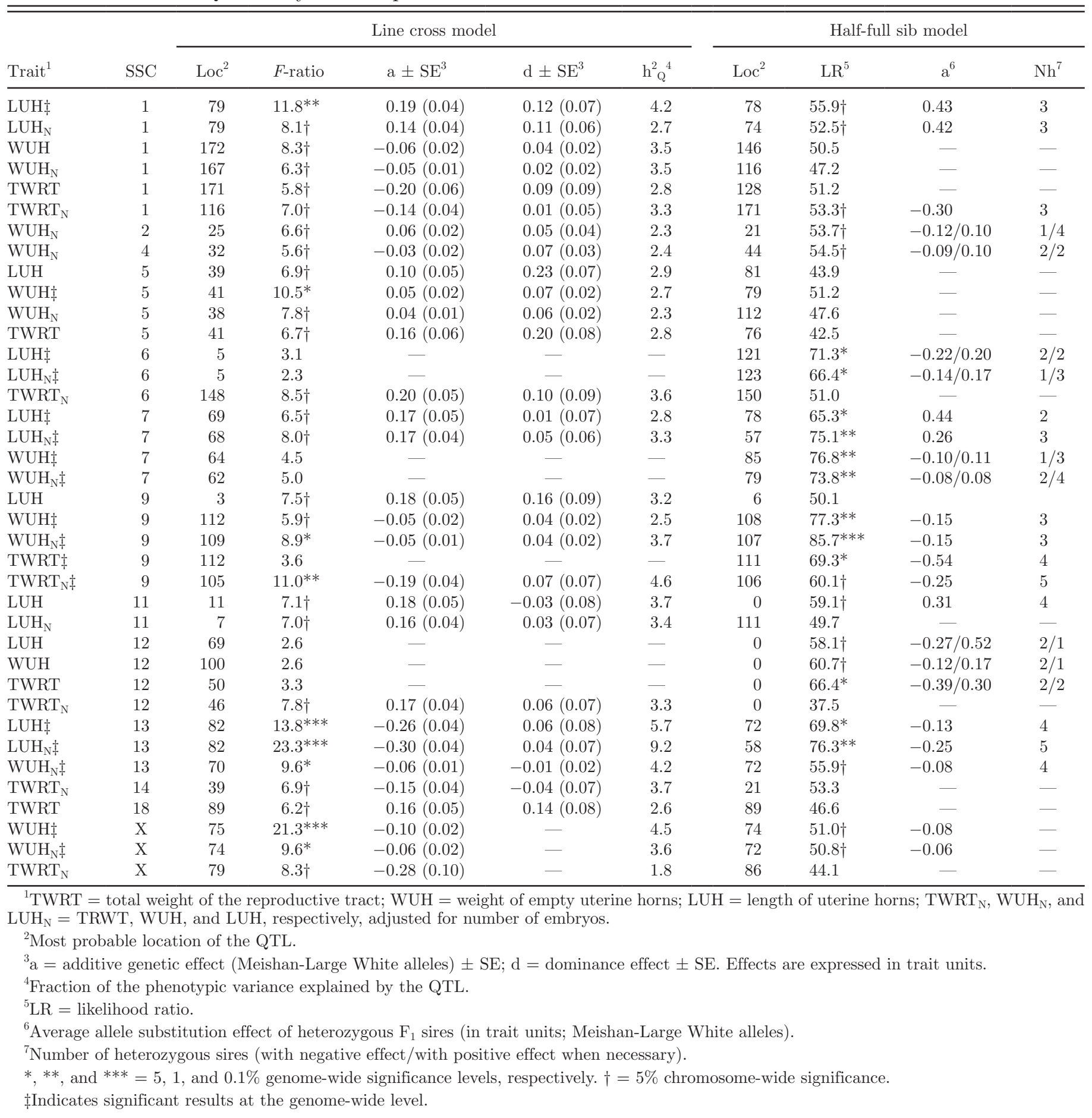

(i.e., at around $60 \mathrm{cM}$ from SW2093)]. Meishan alleles had positive effects on SSC13, but had family-dependent effects on SSC9.

The QTL located on SSC X had a GW significant effect on WUH. It also affected TWRT, though to a lesser extent. Meishan alleles had a negative effect on both WUH and TWRT. Finally, the GW significant QTL detected using HFS on SSC 6 and SSC 12 were QTL with opposite effects according to sire family. The SSC 6 QTL mainly had effects on LUH, whereas both TWRT and, to a lesser extent LUH and WUH, were affected by the SSC 12 QTL.
Additional CW significant QTL were detected on SSC 2, 5, 11, and 15 . They explained a low to moderate proportion of trait phenotypic variance (between 2.3 and $3.7 \%$ ). Their effects will not be further detailed.

\section{DISCUSSION}

This study used a low-density microsatellite marker panel, and an experimental design with a limited number of large families adapted to linkage analysis. It has resulted in large QTL mapping interval (20 to $40 \mathrm{cM}$ ), 


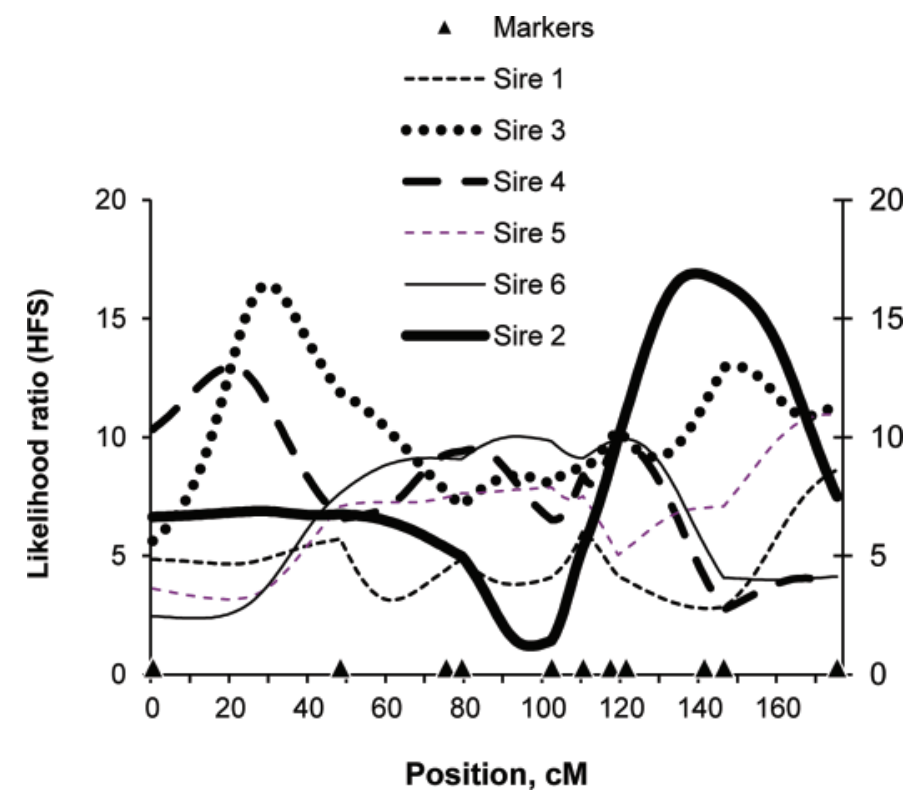

Figure 1. Within-sire likelihood ratio profiles for the total weight of the reproductive tract (TWRT) on SSC 1. Color version available in the online PDF. so that a lot of work is necessary before expecting to find the causal mutation for these QTL.

Newly available high-density SNP chips (Ramos et al., 2009) allow much more accurate QTL mapping through association or linkage disequilibrium linkage analysis methods, provided that an adequate experimental design has been used (i.e., large numbers of small nuclear families). The gain in accuracy due to the use of high-density SNP chips would probably be more limited with the current $\mathrm{F}_{2}$ design, as a strong linkage disequilibrium remains in $\mathrm{F}_{2}$ populations, although some additional information could have been from historical recombinations in founder animals. In spite of these limits, the study provides new and original information on the genetic architecture of traits of interest for pig production that contributes to the growing list of pig QTL (see QTLdb at http://www.animalgenome. org).

As in previous studies, we used 2 complementary models to detect QTL: a simple LC model that assumes different QTL alleles to be fixed in grand-parental populations and a HFS model that takes into account the hierarchical family structure of pig populations. As discussed by Bidanel et al. (2008), the LC model is more powerful when different QTL alleles are fixed in

Table 5. Results of QTL analyses for ovarian and embryo weight

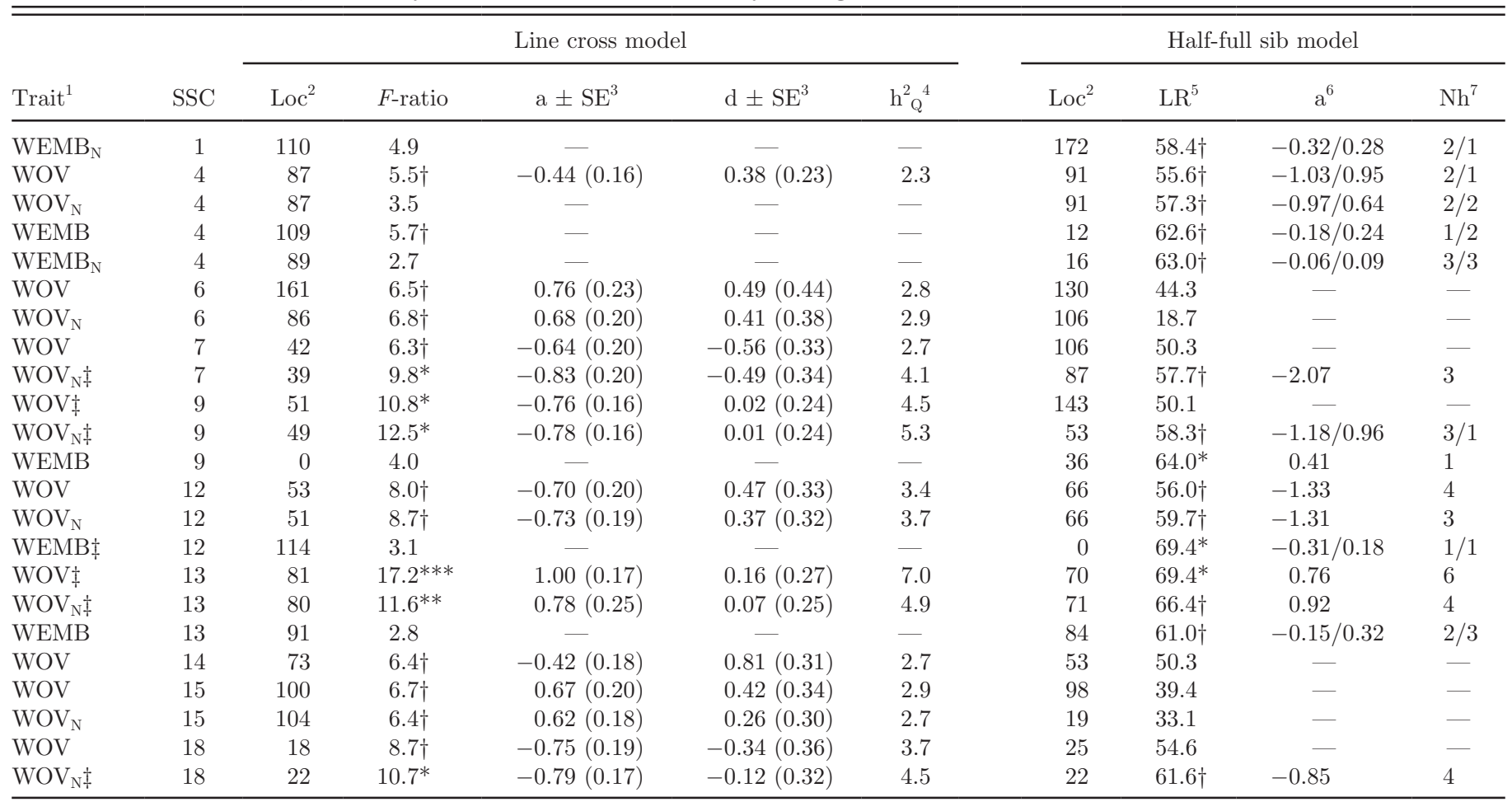

${ }^{1} \mathrm{WOV}=$ weight of ovaries; $\mathrm{WEMB}=$ weight of embryos; $\mathrm{X}_{\mathrm{N}}=$ trait adjusted for ovulation rate (WO) or number of embryos (other traits).

${ }^{2}$ Most probable location of the QTL.

${ }^{3} \mathrm{a}=$ additive genetic effect (Meishan-Large White alleles) $\pm \mathrm{SE} ; \mathrm{d}=$ dominance effect $\pm \mathrm{SE}$. Effects are expressed in trait units.

${ }^{4}$ Fraction of the phenotypic variance explained by the QTL.

${ }^{5} \mathrm{LR}=$ likelihood ratio.

${ }^{6}$ Average allele substitution effect of heterozygous $\mathrm{F}_{1}$ sires (in trait units; Meishan-Large White alleles).

${ }^{7}$ Number of heterozygous sires (with negative effect/with positive effect when necessary).

$*, * *$, and ${ }^{* * *}=5,1$, and $0.1 \%$ genome-wide significance levels, respectively. $\dagger=5 \%$ chromosome-wide significance.

$\ddagger$ Indicates significant results at the genome-wide level. 
founder populations because fewer parameters have to be estimated compared with the HFS model, whereas this latter model allows additional QTL that are segregating in parental populations to be detected. In this study, though the majority of the QTL were detected with both methods, some QTL (e.g., on SSC5) could be only detected only with the LC model, whereas others (e.g., on SSC6 and SSC12) were revealed only with the HFS model. This latter model additionally confirms the result of Bidanel et al. (2008) that, in spite of large breed differences for reproductive performance, QTL alleles with large effects on reproduction traits are still segregating in founder breeds.

A large number of QTL affecting female reproductive tract characteristics during gestation were detected, which illustrates the complex genetic determinism of traits contributing to reproductive efficiency in pigs. Most of them are new results, as a very limited number of QTL affecting reproductive tract characteristics have been reported so far. Indeed, only Rohrer et al. (1999) and Wilkie et al. (1999) previously reported QTL on female reproductive tract measurements on SSC5, SSC7, and SSC8. The SSC5 QTL affecting uterine length detected by Wilkie et al. (1999) was mapped in the same chromosomal region as the QTL affecting LUH, WUH, and TWRT in the present study (42 cM vs. 46 to 48 $\mathrm{cM})$. Conversely, the confidence interval of the SSC7 QTL on uterine length and SSC8 QTL on uterine capacity and weight of ovaries did not correspond to any of the QTL regions detected in the current study.

The large number of QTL detected for reproductive tract characteristics contrasts with the reduced number of QTL found by Bidanel et al. (2008) for the number of viable embryos (2 CW significant QTL) and embryo survival (1 GW and $1 \mathrm{CW}$ significant QTL). Bidanel et al. (2008) clearly illustrate that it is much easier to find QTL for these rather highly heritable traits than for lowly heritable reproductive traits. This of course does not imply that all the QTL we have identified also influence prolificacy. First of all, reproductive tract measurements have only moderate correlations with litter size. Then, traits measured during gestation are imperfect predictors of traits measured at birth, as shown for litter size by Johnson et al. (1999) in pigs or Blasco et al. (2005) in rabbits. Nevertheless, it has to be noticed that the QTL regions carrying the litter size QTL found by Bidanel et al. (2008) on SSC 12 and SSC 18 were the same regions as those found to influence TWRT, WUH, and LUH on SSC 12 and TWRT on SSC 18. The correspondence was even better between ovulation rate measurements and WOV, with QTL at common locations on SSC4 ( 74 vs. $87 \mathrm{cM})$, SSC7 (54 vs. $42 \mathrm{cM}$ ), and SSC13 (72 vs. $70 \mathrm{cM}$ ). Moreover, several QTL of the QTL regions identified in this study were found to carry reproduction QTL in other studies. For instance, the SSC6 QTL affecting the length of uterine horns was close to the QTL affecting litter size detected by Wilkie et al. (1999), Tribout et al. (2008), and Li et al. (2009). The QTL affecting ovarian weight in the SW1354-SW1369 interval on SSC7 contains the properdin locus, which was shown to be associated with litter size at birth by Buske et al. (2005). The most likely positions of the QTL affecting the weight of uterine horns on SSC12 and SSC13 are almost the same as those reported for QTL affecting litter size at birth, respectively, by Fernandez-Rodriguez et al. (2010) and Noguera et al. (2009).

It has also to be emphasized that several of the QTL we have identified are located in chromosomal regions carrying a large number of QTL affecting other economically important traits. This is particularly the case for SSC1, SSC4, SSC6, and SSC13. This raises at least 2 questions: 1) are the QTL involved linked or pleiotropic QTL; 2) is it possible to find haplotypes that have favorable effects on all the affected traits? This second point is of major importance for selection because haplotypes with mainly favorable effects will be of high interest, whereas antagonistic effects may largely impair the efficiency of marker-assisted or genomic selection. These can be addressed using more sophisticated models than the simple 1 trait/1 QTL model used in this study, such as those developed by Gilbert and Le Roy (2003), and by taking advantage of high-density SNP chips. A large variety of breeds should be investigated to have a clear vision of the variability and phenotypic effects of the various haplotypes encountered in pig populations.

The objective of this study was to map new QTL for traits that were not thoroughly investigated before and did not have a direct application in breeding programs. Such a direct application would be difficult for at least 3 reasons; 1 ) the traits investigated are not of direct interest for breeders, but are indirect predictors of major traits of interest; 2) the use of an $F_{2}$ population between divergent breeds makes it difficult to use the results in commercial breeds because many QTL are likely to differ between experimental and commercial populations (although some common QTL have been detected; e.g., Evans et al., 2003); 3) the low accuracy of QTL localization would only allow within-family marker-assisted selection to be used, which is known to have a limited efficiency in pig breeding schemes. Currently, the most promising strategy for using marker information in breeding schemes is through the use of high-density SNP chips through genomic selection. Some recent results tend to show that genomic selection can improve the efficiency of pig breeding schemes (reviewed by, e.g., Tribout et al., 2011), provided that genotyping costs are limited enough to allow the use of SNP chips on a large scale.

In conclusion, this study has shown that reproductive tract measurements during gestation are influenced by a large number of QTL. Several of these QTL were located in chromosomal regions that have been shown to affect female reproductive performance, so that QTL or association studies on these highly heritable traits may be helpful to map or even identify reproduction QTL. Yet, additional investigation using more sophisticated 
genetic models as well as functional studies would be useful to better understand the relationships between reproductive tract characteristics and litter size or embryonic growth and viability.

\section{LITERATURE CITED}

Bennett, G. L., and K. A. Leymaster. 1989. Integration of ovulation rate, potential embryonic viability and uterine capacity into a model of litter size in swine. J. Anim. Sci. 67:1230-1241.

Bidanel, J. P., J. C. Caritez, and C. Legault. 1989. Estimation of crossbreeding parameters between Large White and Meishan porcine breeds. 1. Reproductive performance. Genet. Sel. Evol. 21:507-526.

Bidanel, J. P., D. Milan, N. Iannuccelli, Y. Amigues, M. Y. Boscher, F. Bourgeois, J. C. Caritez, J. Gruand, P. Le Roy, H. Lagant, R. Quintanilla, C. Renard, J. Gellin, L. Ollivier, and C. Chevalet. 2001. Detection of quantitative trait loci for growth and fatness in pigs. Genet. Sel. Evol. 33:289-309.

Bidanel, J. P., A. Rosendo, N. Iannuccelli, H. Gilbert, J. C. Caritez, Y. Billon, A. Prunier, and D. Milan. 2008. Detection of quantitative trait loci for teat number and female reproductive traits in Meishan $\times$ Large White $\mathrm{F}_{2}$ pigs. Animal 2:813-820.

Bidanel, J. P., and M. F. Rothschild. 2002. Current status of quantitative trait locus mapping in pigs. Pig News Inf. 23:39N-54N.

Blasco, A., J. A. Ortega, A. Climent, and M. A. Santacreu. 2005. Divergent selection for uterine capacity in rabbits. I. Genetic parameters and response to selection. J. Anim. Sci. 83:22972302.

Buske, B., C. Brunsch, K. Zeller, P. Reinecke, and G. Brockmann. 2005. Analysis of properdin (BF) genotypes associated with litter size in a commercial pig cross population. J. Anim. Breed. Genet. 122:259-263.

Churchill, G. A., and R. W. Doerge. 2008. Naive application of permutation testing leads to inflated type I error rates. Genetics 178:609-610.

Evans, G. J., E. Giuffra, A. Sanchez, S. Kerje, G. Davalos, O. Vidal, S. Illan, J. L. Noguera, L. Varona, I. Velander, O. I. Southwood, D. J. de Koning, C. S. Haley, G. S. Plastow, and L. Andersson. 2003. Identification of quantitative trait loci for production traits in commercial pig populations. Genetics 164:621-627.

Fernandez-Rodriguez, A., C. Rodriguez, L. Varona, I. Balcells, J. L. Noguera, C. Ovilo, and A. I. Fernandez. 2010. Analysis of candidate genes underlying two epistatic quantitative trait loci on SSC12 affecting litter size in pig. Anim. Genet. 41:73-80.

Gilbert, H., and P. Le Roy. 2003. Comparison of three multitrait methods for QTL detection. Genet. Sel. Evol. 35:281-304.

Green, P., K. Falls, and S. Crooks. 1990. Documentation for CRIMAP version 2.4. Washington University School of Medicine, St. Louis.

Haley, C. S., S. A. Knott, and J. M. Elsen. 1994. Mapping quantitative trait loci in crosses between outbred lines using least squares. Genetics 136:1195-1207.

Johnson, R. K., M. K. Nielsen, and D. S. Casey. 1999. Responses in ovulation rate, embryonal survival, and litter traits in swine to 14 generations of selection to increase litter size. J. Anim. Sci. $77: 541-557$.

Knott, S. A., L. Marklund, C. S. Haley, K. Andersson, W. Davies, H. Ellegren, M. Fredholm, I. Hansson, B. Hoyhem, K. Lundström, M. Moller, and L. Andersson. 1998. Multiple marker mapping of quantitative trait loci in a cross between outbred Wild Boar and Large White pigs. Genetics 149:1069-1080.

Lee, G. J., and C. S. Haley. 1995. Comparative farrowing to weaning performance in Meishan and Large White pigs and their crosses. Anim. Sci. 60:269-280.

Le Roy, P., J. M. Elsen, D. Boichard, B. Mangin, J. P. Bidanel, and B. Goffinet. 1998. An algorithm for QTL detection in mixture of full and half sib families. Pages 257-260 in Proc. 6th World Congr. Genet. Appl. Livest. Prod., Armidale, Australia. Vol. 26. University of New England, Armidale, New South Wales, Australia.

Li, K., J. Ren, Y. Xing, Z. Zhang, J. Ma, Y. Guo, and L. Huang. 2009. Quantitative trait loci for litter size and prenatal loss in a White Duroc $\times$ Chinese Erhualian resource population. Anim. Genet. 40:963-966.

Milan, D., J. P. Bidanel, N. Iannuccelli, J. Riquet, Y. Amigues, M. Y. Boscher, F. Bourgeois, J. C. Caritez, J. Gruand, P. Le Roy, H. Lagant, R. Quintanilla, C. Renard, J. Gellin, L. Ollivier, and C. Chevalet. 2002. Detection of quantitative trait loci for carcass composition traits in pigs. Genet. Sel. Evol. 34:705-728.

Noguera, J. L. L., M. C. Rodríguez, L. Varona, A. Tomas, G. Muñoz, O. Ramirez, C. Barragan, M. Arqué, J. P. Bidanel, M. Amills, C. Ovilo, and A. Sánchez. 2009. A bi-dimensional genome scan for prolificacy traits in pigs shows the existence of multiple epistatic QTL. BMC Genomics 10:636.

Quintanilla, R., J. P. Bidanel, D. Milan, N. Iannuccelli, Y. Amigues, J. Gruand, C. Renard, C. Chevalet, and M. Bonneau. 2003. Genetic mapping of quantitative trait loci for fat androstenone level in pigs. J. Anim. Sci. 81:385-394.

Ramos, A. M., R. P. Crooijmans, N. A. Affara, A. J. Amaral, A. L. Archibald, J. E. Beever, C. Bendixen, C. Churcher, R. Clark, P. Dehais, M. S. Hansen, J. Hedegaard, Z. L. Hu, H. H. Kerstens, A. S. Law, H. J. Megens, D. Milan, D. J. Nonneman, G. A. Rohrer, M. F. Rothschild, T. P. L. Smith, R. D. Schnabel, C. P. Van Tassell, J. F. Taylor, R. T. Wiedmann, L. B. Schook, and M. A. M. Groenen. 2009. Design of a high density SNP genotyping assay in the pig using SNPs identified and characterized by next generation sequencing technology. PLoS ONE 4:e6524.

Rohrer, G. A., J. J. Ford, T. H. Wise, J. L. Vallet, and R. K. Christenson. 1999. Identification of quantitative trait loci affecting female reproductive traits in a multigeneration Meishan-White composite swine population. J. Anim. Sci. 77:1385-1391.

Seaton, G. G. R., C. S. Haley, S. A. Knott, M. Kearsey, and P. M. Visscher. 2002. QTL Express: Mapping quantitative trait loci in simple and complex pedigrees. Bioinformatics 18:339-340.

Tribout, T., J. P. Bidanel, F. Phocas, S. Schwob, F. Guillaume, and C. Larzul. 2011. Genomic selection: Principles and prospects for pig genetic improvement. J. Rech. Porc. 43:13-25.

Tribout, T., N. Iannuccelli, T. Druet, H. Gilbert, J. Riquet, R. Guéblez, M. J. Mercat, J. P. Bidanel, D. Milan, and P. Le Roy. 2008. Detection of quantitative trait loci for reproduction and production traits in Large White and French Landrace pig populations. Genet. Sel. Evol. 40:61-78.

Wilkie, P. J., A. A. Paszek, C. W. Beattie, L. J. Alexander, M. B. Wheeler, and L. B. Schook. 1999. A genomic scan of porcine reproductive traits reveals possible quantitative trait loci (QTLs) for number of corpora lutea. Mamm. Genome 10:573-578.

Wu, M. C., M. D. Hentzel, and P. J. Dziuk. 1987. Relationships between uterine length and number of foetuses and prenatal mortality in pigs. J. Anim. Sci. 65:762-770. 
References

This article cites 26 articles, 11 of which you can access for free at: http://www.journalofanimalscience.org/content/90/1/37\#BIBL 